\title{
Impact assessment on water resources management under extreme climate change
}

\author{
Zhiming Liu ${ }^{1}$, Yongqiang Wang ${ }^{1, \mathrm{a}}$, Jin $\mathrm{Chen}^{1}$, Jijun $\mathrm{Xu}^{1}$, and Shaokun $\mathrm{He}^{2}$ \\ ${ }^{1}$ Hubei Provincial Key Laboratory of Basin Water Resources and Ecological Environment, Yangtze River Scientific Research Institute, \\ Wuhan, China \\ ${ }^{2}$ State Key Laboratory of Water Resources and Hydropower Engineering Science, Wuhan University, Wuhan, China
}

\begin{abstract}
River flows would be influenced greatly by climate change, which may cause further stress on water resources management by altering the quantity and distribution of runoff. In this paper, taking the Hanjiang River basin for instance, projections of precipitation and temperature are generated from two GCMs under RCP8.5 scenario, an extreme condition. Then the outputs are statistically downscaled and corrected by the daily bias correction method, a hybrid method of combining the daily translation and the local intensity scaling method. The VIC distributed hydrological model is used for the runoff simulation. Results show that the projections of two GCMs consistent with each other. There is a general increase in the annual mean precipitation and temperature in the Hanjiang River Basin in the future period (2021-2099), and the annual mean runoff of the Danjiangkou reservoir increases significantly compared with historical period (1980-2010). However, the annual runoff variability would increase the flood control pressure in wet season, aggravate the conflict between power generation and water supply in dry season despite increasing the water supply capacity in storage season.
\end{abstract}

\section{Introduction}

Recent decades have witnessed an increase in global average temperature, as documented by the Fifth Assessment Report (AR5) of the Intergovernmental Panel on Climate Change (IPPC) in 2013, the changes in climate system would substantially affect global hydrological cycle by the end of the 21 st century, which may impose a significant impact on river flows and consequently intensify the pressure on water resources management by altering the temporal and spatial distribution of the water availability [1].

To assess climate change impacts on hydrology, General Circulation Models (GCMs) are used to simulate the present climate and to project the future climate change, then results are downscaled by dynamical or statistical downscaling methods for the resolution of GCM outputs are often too coarse and biased, and in final the corrected meteorological elements are driven by hydrological models for impact assessment. Many research groups have done lots of investigations and have proposed many different methods and models to improve the accuracy because of the existence of various sources of uncertainty, especially the uncertainty related to GCM and downscaling technique [2]. Therefore, it is crucial to choose suitable GCMs and downscaling techniques.

The Danjiangkou Reservoir, as the water source for the middle route of the South-to-North Water Diversion Project in China, began water supply in 2014. According to the water supply plan, the annual average water supply of 9.5 billion $\mathrm{m}^{3}$ will significantly relieve chronic water shortage problems in several provinces and cities, including the capital city of Beijing. However, the quantity of water diversion was calculated without considering climate change, thus impact assessment under climate change become vital to implement or revise the water diversion decision, especially under extreme condition. In this paper, taking the Hanjiang River basin for instance, projections of temperature and precipitation are generated from two GCMs under RCP8.5 scenario and corrected by the daily bias correction method, then driven by VIC distributed hydrological model for runoff simulation. Runoff variability of the Danjiangkou Reservoir and impact assessment on water resources management under climate change are discussed and analysed.

\section{Study area and data}

\section{1 study area}

The Hanjiang River Basin is located in the south-central China, with a drainage area is about $159,000 \mathrm{~km}^{2}$. The Hanjiang River has a main stream length of $1577 \mathrm{~km}$, it originates from the southern Qinling Mountain, flows through Shanxi and Hubei provinces, and ultimately joins the Yangtze River at Wuhan city. The Hanjiang River Basin has a subtropical monsoon climate, the annual mean temperature varies from $14^{\circ} \mathrm{C}$ to $16^{\circ} \mathrm{C}$ and the

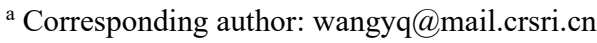


annual average precipitation ranges between $700 \mathrm{~mm}$ and $1100 \mathrm{~mm}(70 \%-80 \%$ total rainfall occurs in the wet season, from May to October) [3].

The sub-basin above the Danjiangkou Reservoir is used in this study, with a drainage area of $89,540 \mathrm{~km}^{2}$. The Danjiangkou Reservoir lies in the middle reach of the Hanjiang River Basin, at the junction between the Hanjiang River and Danjiang River. It is an incomplete multi-year regulation reservoir, with a total storage capacity of 31.95 billion $\mathrm{m}^{3}$. Since it serves as the water source of the South-to-North Water Diversion Project, its main functions have been adjusted to flood control, water supply, hydropower generation, irrigation, etc. The annual average water supply of 9.5 billion $\mathrm{m}^{3}$ will inevitably intensify the pressure and aggravate the conflict on water resources management in the future, even if it is not under climate change.

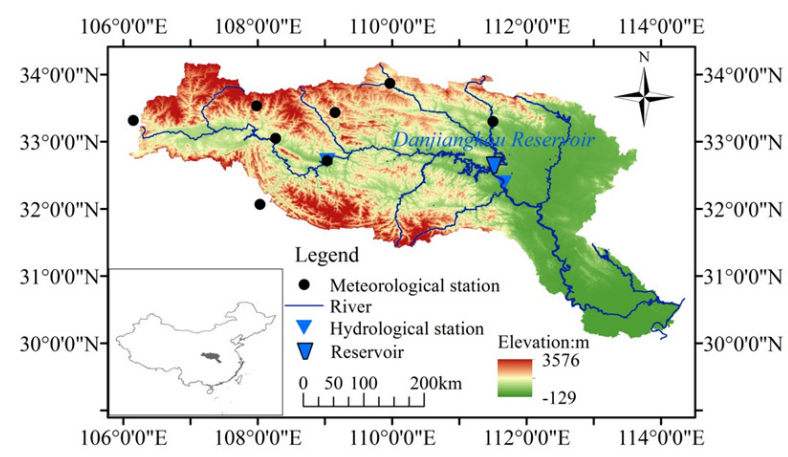

Figure 1. Location of the Hanjiang River Basin and the Danjiangkou Reservoir.

\section{2 data}

Both observed and GCMs-simulated daily precipitation (prep), maximum and minimum temperature $\left(T_{\max }, T_{\min }\right)$ datasets of the Hanjiang River Basin are used in this study. The observed data from eight weather stations (evenly distributed in Fig.1) during 1971-2005 (reference period) are obtained from China Meteorological Data Sharing Service System. The GCM-simulated data covered 1971-2005 for the history and 2021-2100 for the future. The streamflow at the sub-basin outlet is the inflow of the Danjiangkou Reservoir, which is provided by the Bureau of Hydrology of the Changjiang Water Resources Commission.

Projections of temperature and precipitation are generated from two GCMs under RCP8.5 scenario, an extreme climate change condition. The BBC-CMS1.1(m) (GCM-BBC) and the BNU-ESM (GCM-BNU) are selected for their wide application and relatively good performance in reproducing observed temperature and precipitation in China in recent decades [4-5].

\section{Methodology}

\subsection{Bias correction method}

The daily bias correction method (DBC) is a hybrid method, combining the daily translation method (DT) and the local intensity scaling method (LOCI). The LOCI method is first taken to correct the precipitation occurrence, ensuring that the frequency of the precipitation occurrence of corrected data at the reference period is equal to that of the observed data for a month. Then, instead of applying the same factor (LOCI) to correct each daily precipitation for a specific month, the DT method is adopted to modulate the changes as a function of percentile differences in the frequency distribution of precipitation (or temperature) between observation and GCMs [2].

For the LOCI method: (1) A wet-day threshold is determined from the daily GCM precipitation for a specific month, so that the threshold exceedance equals the observed series; (2) A scaling factor is calculated to ensure that the mean of the observed precipitation is equal to that of GCM precipitation at the reference period for each month; and (3) The monthly thresholds and factors determined in the reference climate are used to adjust monthly precipitation for the future period [6].

For the DT method, the ratio (for precipitation) or difference (for temperature) in percentiles between observed and GCM-simulated data at the reference period is multiplied or added to the future time series for each percentile [7].

$$
\begin{aligned}
& T_{a d j, f u t, d}=T_{G C M, f u t, d}+\left(T_{o b s, Q}-T_{G C M, r e f, Q}\right) \\
& P_{a d j, f u t, d}=P_{G C M, f u t, d} \times\left(P_{o b s, Q} / P_{G C M, r e f, Q}\right)
\end{aligned}
$$

Where the subscripts $d$ and $Q$ represent day and a percentile for a specific month; fut, obs and ref represent future, observed and reference period; adj and GCM represent corrected and uncorrected GCM data.

\subsection{Hydrological modelling}

The variable infiltration capacity model (VIC), a macroscale distributed hydrological model, has been widely used for flow forecasting and climate change impact studies. The VIC model has bare soil and different vegetation types in each grid cell. It contains both the saturation and infiltration excess runoff processes in a grid cell with a consideration of the sub grid-scale soil heterogeneity, and the frozen soil processes under the cold climate condition. The evaporation consists of three parts: evaporation from the canopy layer of each vegetation class, evaporation from dry canopy and evaporation from bare soil. The moisture transfer between soil layers obeys the Darcy law and the vertical soil is described by the one-dimensional Richard equation. The routing model represented by the unit hydrograph method for overland flow, and the linear Saint-Venant method for channel flow [8].

VIC model can simulate hydrological processes at a wide range of spatial scales. It has been well developed by its application on watershed, ranging from small scales to continental and global scales.

\section{Results and discussion}




\subsection{Bias correction method verification}

The observed and GCMs-simulated daily precipitation (prep), maximum and minimum temperature $\left(T_{\max }, T_{\min }\right)$ datasets of the Hanjiang River Basin during 1971-2005 are used to verify the performance of the DBC method. Nine statistics (mean, standard deviation, 25th, 50th, 75th, 90th, 95th and 99th percentiles and maximum value) are selected [9]. The biases of raw and corrected GCMs' precipitation and temperature on the daily time scale are presented in Fig.2, where the x-axis represents eight meteorological stations and the $y$-axis represents the GCM's biases with respect to nine statistics. Darker colour means larger bias. From the picture we can see, raw outputs of two GCMs have the considerable negative bias (precipitation is above $15 \%$, temperature is above $2{ }^{\circ} \mathrm{C}$ ). After corrected, them are significantly improved, especially for minimum temperature. All above results illustrate the excellent performance of the DBC method.
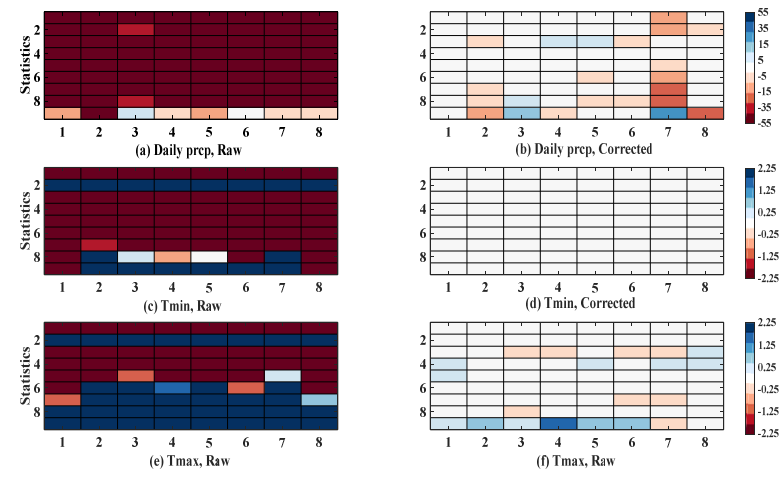

(1) GCM-BBC
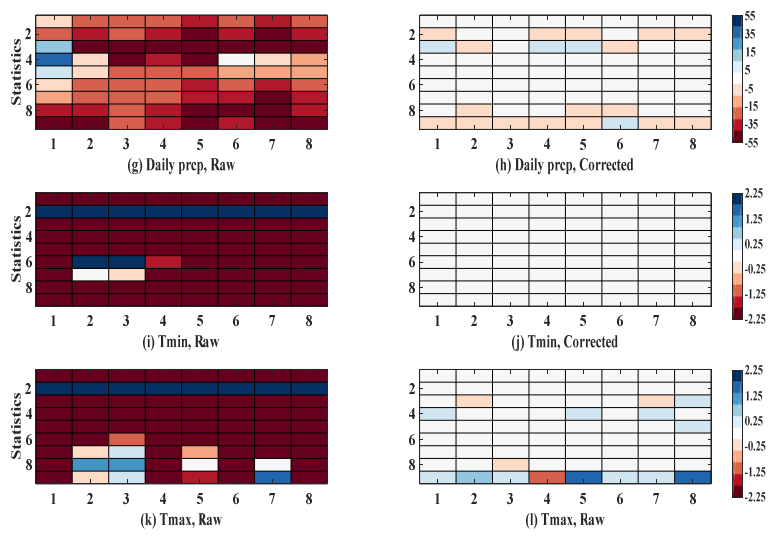

(2) GCM-BNU

Figure 2. Bias of raw and corrected outputs of two GCMs.

\subsection{Climate change projection}

The daily precipitation (prep), maximum and minimum temperature $\left(T_{\max }, T_{\min }\right)$ during 2021-2100 are generated from two corrected GCMs. Table 1 indicates a general increase in annual mean precipitation (most are above 5\%) in the Hanjiang River Basin in the future period except an apparently decrease in Wanyuan station under GCM$\mathrm{BCC}$, and a consistent increase in annual mean temperature (most are above $1{ }^{\circ} \mathrm{C}$ ) of all meteorological station under two GCMs. Values of two GCMs in table 1 represent the relative increment for precipitation and absolute increment for temperature. This indicate that the
Hanjiang River basin is projected to follow a warmer trend and have more rainfall under RCP8.5 scenario despite the temporal and spatial distribution variability.

Table 1. Projected future changes of annual mean precipitation and temperature at 8 meteorological stations under two GCMs.

\begin{tabular}{|c|c|c|c|c|}
\hline Station & Variable & $\begin{array}{c}\text { Historical } \\
\text { period }\end{array}$ & $\begin{array}{l}\text { GCM- } \\
\text { BCC }\end{array}$ & $\begin{array}{l}\text { GCM- } \\
\text { BNU }\end{array}$ \\
\hline \multirow{2}{*}{ Lueyang } & Prep(mm) & 792 & $3.5 \%$ & $6.3 \%$ \\
\hline & Temp $\left({ }^{\circ} \mathrm{C}\right)$ & 14.3 & 0.1 & 0.1 \\
\hline \multirow{2}{*}{ Foping } & $\operatorname{Prep}(\mathrm{mm})$ & 894 & $7.4 \%$ & $7.9 \%$ \\
\hline & $\operatorname{Temp}\left({ }^{\circ} \mathrm{C}\right)$ & 13.0 & 1.6 & 2.0 \\
\hline \multirow{2}{*}{ Shangzhou } & Prep(mm) & 673 & $14.3 \%$ & $12.3 \%$ \\
\hline & $\operatorname{Temp}\left({ }^{\circ} \mathrm{C}\right)$ & 13.6 & 1.9 & 2.5 \\
\hline \multirow{2}{*}{ Zhenan } & Prep(mm) & 767 & $8.3 \%$ & $9.5 \%$ \\
\hline & Temp $\left({ }^{\circ} \mathrm{C}\right)$ & 14.0 & 1.5 & 2.2 \\
\hline \multirow{2}{*}{ Xixia } & Prep(mm) & 844 & $14.3 \%$ & $9.5 \%$ \\
\hline & $\operatorname{Temp}\left({ }^{\circ} \mathrm{C}\right)$ & 15.9 & 1.5 & 1.9 \\
\hline \multirow{2}{*}{ Shiquan } & Prep(mm) & 878 & $6.6 \%$ & $7.1 \%$ \\
\hline & $\operatorname{Temp}\left({ }^{\circ} \mathrm{C}\right)$ & 15.5 & 0.3 & 0.9 \\
\hline \multirow{2}{*}{ Wanyuan } & Prep(mm) & 1242 & $-19.0 \%$ & $1.3 \%$ \\
\hline & $\operatorname{Temp}\left({ }^{\circ} \mathrm{C}\right)$ & 15.5 & 1.1 & 1.1 \\
\hline \multirow{2}{*}{ Ankang } & Prep(mm) & 812 & $5.5 \%$ & $8.6 \%$ \\
\hline & $\operatorname{Temp}\left({ }^{\circ} \mathrm{C}\right)$ & 16.5 & 0.0 & 0.7 \\
\hline
\end{tabular}

\subsection{Impact assessment on water resources management}

The observed daily precipitation and temperature dataset are driven by VIC model, and data from 1980-1995 and 1996-2005 are used to calibration and validation the runoff of the Danjiangkou Reservoir, respectively. The Nash-Sutcliffe efficiency (NSE) and the relative error (RE) of runoff are 0.82 and 0.06 in calibration period, 0.81 and 0.09 in validation periods, respectively. The results demonstrate that the VIC model can simulate runoff well.

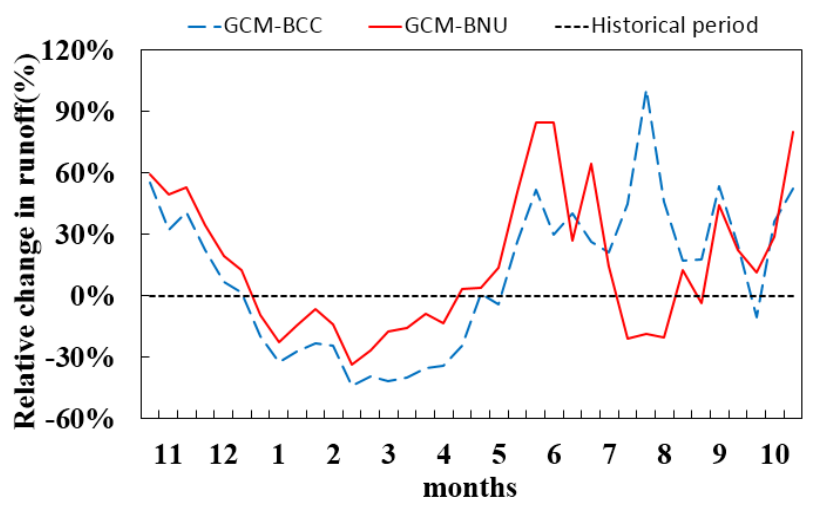

Figure 3. Relative change in 10-days runoff under two GCMs.

The projections of streamflow at the Danjiangkou Reservoirs during 2021-2100 are obtain by the calibrated VIC model. As showed in Figure 3, the relative change trends in 10-days runoff under two GCMs are almost synchronous except in late July and whole August. So, it can be divided into 3 periods: dry season (from January 
to April), wet season (from May to September), and storage season (from October to December), which exactly accords with the operation periods of the Danjiangkou Reservoir. The relative change in 3 periods are $-32.8 \%, 34.8 \%$ and $23.0 \%$ under GCM-BBC, $-13.4 \%$, $18.7 \%$ and $36.0 \%$ under GCM-BNU, respectively. It would increase the flood control pressure in wet season, aggravate the conflict between power generation and water supply in dry season, and increase the water supply capacity in storage season. The annual mean runoff will increase by $22.8 \%$ and $17.4 \%$ under two GCMs, respectively. It demonstrates that river flows would be influenced greatly by climate change.

\section{Conclusion}

This study investigated and assessed the impact of water resources management under extreme climate change. Projections of precipitation and temperature from two GCMs under RCP8.5 extreme scenario are statistically downscaled by the daily bias correction method. Then they are driven by VIC model for runoff simulation. Our study shows that the results of two GCMs consistent with each other. There is a general increase in the annual mean precipitation and temperature in the Hanjiang River Basin in the future period despite the temporal and spatial distribution variability, and the annual mean runoff of the Danjiangkou Reservoir changes significantly compared with historical period, increasing by $22.8 \%$ under GCM$\mathrm{BBC}$ and $17.4 \%$ under GCM-BNU. According to the annual inflow variability and the operation period of the Danjiangkou Reservoir, we divide 3 periods (dry, wet, storage period) for impact assessment. The relative change of runoff in 3 periods are $-32.8 \%, 34.8 \%$ and $23.0 \%$ under GCM-BBC, $-13.4 \%, 18.7 \%$ and $36.0 \%$ under GCM-BNU, respectively. It implies the extreme climate change would increase the flood control pressure in wet season, aggravate the conflict between power generation and water supply in dry season, and increase the water supply capacity in storage season. To tackle adverse effects on water resources management under extreme climate change, we can adjust current operation rules of the Danjiangkou Reservoir to adapt the annual runoff variability.

\section{Acknowledgements}

This work is funded by the National Key R\&D Program of China (2017YFC0403600, 2017YFC0403606), the National Natural Science Foundation of China (No. 51779013, 51509009), National Public Research Institutes for Basic R\&D Operating Expenses Special Project (No. CKSF2017008), Water Conservancy Science and Technology Innovation project of Guangdong Province (2017-03). Special thanks are given to the anonymous reviewers and editors for their constructive comments.

\section{References}

1. V.P. Singh, A.K. Mishra, H. Chowdhary, C.P. Khedun. Climate Change and Its Impact on Water Resources. Humana Press, 2014, 1 (5) :525-569.

2. J. Chen, F.P. Brissette, D. Chaumont, M. Braun. Performance and uncertainty evaluation of empirical downscaling methods in quantifying the climate change impacts on hydrology over two North American river basins. Journal of Hydrology , 2013 , 479 (5) :200-214.

3. L. Wang, C.C. Huang, J. Pang, J. Zha, Y. Zhou. Paleofloods recorded by slack water deposits in the upper reaches of the Hanjiang River valley, middle Yangtze River basin, China. Journal of Hydrology, 2014, 519:1249-1256.

4. C. Ma, S. Pan, G. Wang, Y.P. Xu. Changes in precipitation and temperature in Xiangjiang River Basin, China. Theoretical \& Applied Climatology, 2016, 123(3-4):1-13.

5. G. Yang, S. Guo, L. Li, X. Hong, L. Wang. Multi-Objective Operating Rules for Danjiangkou Reservoir Under Climate Change. Water Resources Management, 2016, 30(3):1183-1202.

6. J. Schmidli, C. Frei, P.L. Vidale. Downscaling from GCM precipitation: a benchmark for dynamical and statistical downscaling methods. International Journal of Climatology, 2010, 26(5):679-689.

7. F.S. Mpelasoka, F.H.S. Chiew. Influence of rainfall scenario construction methods on runoff projections. J Hydrometeor, 2009, 10(5):1168.

8. Y. Zhou, S. Guo. Incorporating ecological requirement into multipurpose reservoir operating rule curves for adaptation to climate change. Journal of Hydrology, 2013, 498(12):153-164.

9. M. Shen, J. Chen, M. Zhuan, H. Chen, C.Y. Xu. Estimating uncertainty and its temporal variation related to global climate models in quantifying climate change impacts on hydrology. Journal of Hydrology, 2018, 566:10-24. 